\title{
Research on the Mechanism Innovation Ability Model of Higher Vocational Students' Entrepreneurship Education in the Big Data Era
}

\author{
Shengsheng Wang
}

School of Electrical and Information Technology Jilin Vocational and Technical College of Industry, Jilin, China

\begin{abstract}
Cultivating innovation ability is an important task faced by higher vocational educators. The level of innovation ability reflects the degree of self-improvement, self-regulation, and selfrealization of higher vocational students. It promotes scientific education and plays a guiding role in cultivating innovative talents. Based on the background of the era of big data, the thesis builds an index system for higher vocational students' entrepreneurial education ability, and is committed to establishing a scientific evaluation system. This provides theoretical basis and practical guidance for educators.
\end{abstract}

Keywords: Big Data; Higher Vocational Students; Entrepreneurship Education; Innovation Ability Model.

\section{Introduction}

The innovation ability assessment of vocational students incorporates the ability tendency into the evaluation system, which helps vocational students to judge whether their ability tendency is in line with the ability required by the major they are learning, and use this as a basis to find the most suitable career direction for them, so that the talents The creative potential is given full play; to understand the actual situation of vocational students' innovative ability, and to provide a wealth of statistical data to the society and schools, to provide a reference for them to take effective measures to cultivate the innovative ability of vocational students, and to form to cultivate innovation The education concept of ability as the core promotes the realization of teachers' teaching goals and the clarification of students' development direction; the final research data will provide data support and theoretical guidance for the innovative teaching work of colleges and universities, so that colleges and universities will be more efficient and targeted Cultivating students' innovative ability can get a clear adjustment idea in terms of educational resources.

\section{The Establishment of an Index System for Innovation Capabilities}

According to the dialectics of materialism, we divide the evaluation indicators of higher vocational students' innovative ability into three First-level indicators: discovering problems, analyzing problems, and solving problems [1]. These three First-level indicators cover our basic steps to solve problems, and can more comprehensively reflect the basic status of vocational students' innovative ability. Furthermore, the three First-level indicators are divided into more detailed and more targeted twelve second-level indicators, each containing a number of specific evaluation indicator elements. The basic structure of the index system is shown in Figure 1.

\section{Determination of Index Weights for Fuzzy Comprehensive Evaluation and Analytic Hierarchy Process}

\subsection{Fuzzy Comprehensive Evaluation}

The questionnaire is designed in the format of a Likert scale. The evaluation index system of higher vocational students' innovation ability is composed of three First-level evaluation indexes and twelve second-level evaluation indexes. The measurement of the indexes adopts the Likert scale. Method, 
Volume 3 (2021)

using semantic scale to divide into 4 measurement levels: good, good, fair, and poor [2]. In order to facilitate calculation, we quantify the semantic scale of subjective evaluation and assign the values 4 , 3,2 , and 1 in turn. We still use the analytic hierarchy process to find the index weights. Construct their own judgment matrix for each secondary index respectively, and then use MATLAB software to calculate the maximum characteristic root and consistency test. Get a reasonable weight coefficient. The judgment matrices for the secondary indicators are:

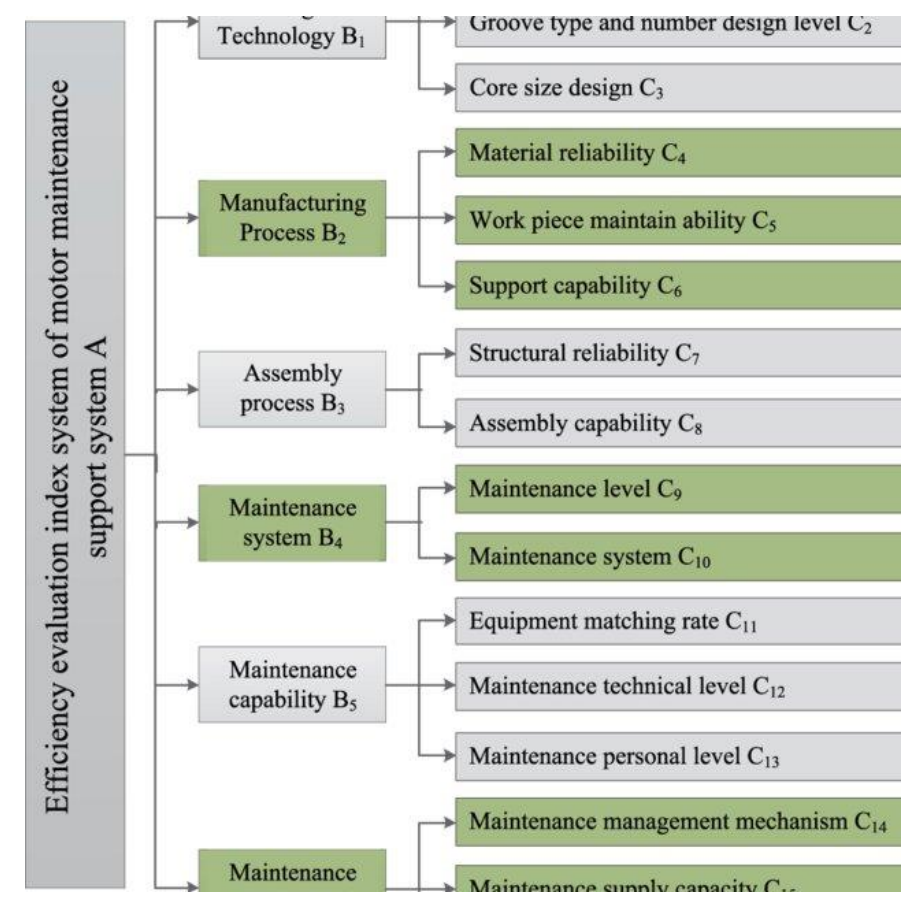

Fig 1. Innovative ability evaluation index system

$$
\begin{aligned}
\mathrm{S}_{1} & =\left[\begin{array}{ccccc}
1 & 1 / 5 & 1 / 6 & 3 / 10 & 2 / 5 \\
5 & 1 & 1 & 17 / 10 & 11 / 5 \\
6 & 1 & 1 & 2 & 12 / 5 \\
10 / 3 & 10 / 17 & 1 / 2 & 1 & 6 / 5 \\
5 / 2 & 11 / 5 & 5 / 12 & 5 / 6 & 1
\end{array}\right] \\
\mathrm{S}_{2} & =\left[\begin{array}{cccc}
1 & 2 & 9 / 2 & 6 \\
1 / 2 & 1 & 1 & 3 \\
2 / 9 & 1 & 1 & 7 / 5 \\
1 / 6 & 1 / 3 & 5 / 7 & 1
\end{array}\right] \\
\mathrm{S}_{3} & =\left[\begin{array}{ccc}
1 & 3 / 10 & 1 / 10 \\
10 / 3 & 1 & 2 / 5 \\
10 & 5 / 2 & 1
\end{array}\right]
\end{aligned}
$$

Find the weight of the five indicators of problem ability, and its feature vector is $(0.1039,0.5645,0.6152,0.3225,0.4338)$. Normalized to get $(0.0509,0.2767,0.3016,0.1581,0.2127)$. Analyze the weight $(0.5398,0.2221,0.1501,0.0880)$ of the problem ability index. The weight $(0.0717,0.2539,0.6744)$ of the Problem-solving ability index. The various elements and weights of the indicator system are described in Table 1 to Table 4.

The final evaluation system of the status quo of vocational students' innovation ability. The index system and weights are shown in Table 5. 
Table 1. Innovative capabilities

\begin{tabular}{|c|c|c|c|}
\hline First level indicator & Serial number & Secondary indicators & Weights \\
\hline \multirow{3}{*}{ Creativity } & 1 & problem found & 0.5472 \\
\cline { 2 - 4 } & 2 & analyse problem & 0.2631 \\
\cline { 2 - 4 } & 3 & Solve the problem & 0.1897 \\
\hline
\end{tabular}

Table 2. Problems found

\begin{tabular}{|c|c|c|}
\hline Serial number & Three-level indicators & Weights \\
\hline 1 & Knowledge update ability & 0.056 \\
\hline 2 & Intuitive thinking ability & 0.3 \\
\hline 3 & Critical thinking skills & 0.3336 \\
\hline 4 & Creative thinking ability & 0.1717 \\
\hline 5 & Inspirational thinking ability & 0.1387 \\
\hline
\end{tabular}

Table 3. Analyze the problem

\begin{tabular}{|c|c|c|}
\hline Serial number & Three-level indicators & Weights \\
\hline 1 & Logical reasoning ability & 0.538 \\
\hline 2 & Information retrieval capabilities & 0.2594 \\
\hline 3 & Basic knowledge level & 0.1172 \\
\hline 4 & Cross knowledge level & 0.0855 \\
\hline
\end{tabular}

Table 4. Resolving problems

\begin{tabular}{|c|c|c|}
\hline Serial number & Three-level indicators & Weights \\
\hline 1 & Subject self-satisfaction & 0.0852 \\
\hline 2 & Results of innovation activities & 0.2706 \\
\hline 3 & Subject unique level & 0.6442 \\
\hline
\end{tabular}

Table 5. Two-level evaluation indexes and weights of vocational students' innovation ability

\begin{tabular}{|c|c|c|}
\hline Comprehensive index & Evaluation index & Weights \\
\hline \multirow{4}{*}{ The ability to find problems (0.5472) } & a1 Knowledge update ability & 0.056 \\
\cline { 2 - 3 } & a2 Intuitive thinking ability & 0.3 \\
\cline { 2 - 3 } & a3 Critical thinking skills & 0.3336 \\
\cline { 2 - 3 } & a4 creative thinking ability & 0.1717 \\
\hline \multirow{3}{*}{ Problem analysis ability (0.2631) } & a5 Inspiration thinking ability & 0.1387 \\
\cline { 2 - 3 } & b1 logical reasoning ability & 0.538 \\
\cline { 2 - 3 } & b2 Information retrieval capabilities & 0.2594 \\
\cline { 2 - 3 } & b3 basic knowledge level & 0.1172 \\
\hline \multirow{2}{*}{ Problem solving ability (0.1897) } & b4 Cross knowledge level & 0.0855 \\
\cline { 2 - 3 } & c1 Subject self-satisfaction & 0.0852 \\
\cline { 2 - 3 } & c2 Achievements of innovation activities & 0.2706 \\
\cline { 2 - 3 } & c3 topic unique level & 0.6442 \\
\hline
\end{tabular}

\subsection{Results of the Questionnaire}

The survey was conducted by questionnaire survey. The sample size is determined by comprehensively considering various factors such as majors and grades, and a reasonable quota design is carried out to ensure that the sample selection reflects the actual situation of the vocational students in Southwest Transportation Vocational College as much as possible.

In the research of survey sample size, for a finite population, the formula of sample sampling size is as follows:

$$
n \geq \frac{N}{\left(\frac{\alpha}{k}\right)^{2} \frac{N-1}{P(1-P)}+1}
$$


Where $\mathrm{N}$ is the number of samples in the population, and when the $\mathrm{P}$ value is set to 0.5 , the most reliable sample size can be obtained when the value is set to 0.5. Confidence is related to the significance level. Under normal circumstances, the significance level is usually set to 0.05 . When the $P$ value of the statistic is less than or equal to, the null hypothesis is rejected; when the significance $\mathrm{P}$ value of the statistic is greater than, the null hypothesis is accepted. $\mathrm{k}$ is the quantile of when the significance level is [3]. A total of 800 questionnaires were issued in the formal survey, and 800 were returned, with a recovery rate of $100 \%$. There were 785 valid questionnaires with an effective rate of $98.125 \%$. Among all the interviewees, the ratio of male to female residents was 61:38. Among them, there are 238 students in the first year of higher vocational education, accounting for $34.1 \%$ of the total; the second year of higher vocational students has the most, reaching 340 , accounting for $48.8 \%$ of the total number; the third year of higher vocational students is 97 , accounting for the total number $13.9 \%$ of the number of students, 22 senior vocational students, $3.2 \%$ of the total number. The questionnaire covers all grades and professional levels, and is universally representative.

\section{Result Analysis}

\subsection{Statistical Analysis of First-level Evaluation Indicators}

The satisfaction of each level index is shown in Table 6. The scoring rate of the analysis question is the highest, which shows that contemporary vocational students have more outstanding ability to analyze the question [4]. Especially this year, major vocational schools have implemented quality education reforms, focusing on the training and cultivation of students' thinking, and have achieved considerable results in this regard.

Table 6. Satisfaction with First-level indicators

\begin{tabular}{|c|c|c|c|c|}
\hline & average value & Total score & Scoring rate & Standard deviation \\
\hline Problem found & 36.3841 & 53 & 0.69 & 7.50637 \\
\hline Analyse problem & 19.4654 & 26 & 0.75 & 4.3779 \\
\hline Solve the problem & 4.1951 & 21 & 0.2 & 2.91185 \\
\hline
\end{tabular}

\subsection{Statistical Analysis of Secondary Indicators}

\subsubsection{Secondary Indicators of the Ability to Find Problems}

The purpose of our learning is not only to follow the old knowledge, old skills and skills of the predecessors, but more importantly, to give students a pair of insights that are good at finding problems. Life not only requires extensive knowledge, but also the ability to find problems [5]. If you don't even have the ability to find problems, then "innovation" is nonsense. The ability to find problems is specifically manifested as: knowledge update ability, intuitive thinking ability, critical thinking ability, creative thinking ability, and inspirational thinking ability. The secondary indicators are shown in Table 7.

Table 7. Secondary indicators of ability to find problems

\begin{tabular}{|c|c|c|c|c|c|c|}
\hline & Mean & \multirow{2}{*}{$\begin{array}{c}\text { Standard } \\
\text { deviation }\end{array}$} & Statistics & $\begin{array}{c}\text { Standard } \\
\text { error r }\end{array}$ & Statistics c & Standard error \\
\cline { 4 - 7 } & & & & & & \\
\hline $\begin{array}{c}\text { Knowledge update } \\
\text { ability }\end{array}$ & 1.7727 & 0.37448 & 0.333 & 0.093 & -0.184 & 0.185 \\
\hline Intuitive thinking ability & 11.2611 & 4.27074 & -0.764 & 0.093 & -0.081 & 0.185 \\
\hline Critical thinking skills & 13.5839 & 3.92555 & -1.275 & 0.093 & 2.822 & 0.185 \\
\hline Creative thinking ability & 5.8422 & 1.74389 & 0.109 & 0.093 & 2.99 & 0.185 \\
\hline $\begin{array}{c}\text { Inspirational thinking } \\
\text { ability }\end{array}$ & 3.9241 & 1.8513 & 0.822 & 0.093 & -0.378 & 0.185 \\
\hline
\end{tabular}


It can be seen from the above table that the average critical thinking ability of the interviewed students is the highest (13.58), followed by critical thinking ability. Knowledge updating ability is the smallest, and the standard deviation of knowledge updating ability is the smallest, while the intuitive thinking ability is the smallest. The standard deviation is the largest, followed by critical thinking ability. This shows that the interviewed students' knowledge updating ability is generally poor, but there is a big difference between critical thinking ability and intuitive thinking ability, and the overall range is in the upper middle range. Therefore, the school will increase the training of students in this area in the future, and further cultivate their creative thinking, rich imagination, rational self-awareness, sound and complete personality, and research interest by cultivating their ability to find problems. To achieve the purpose of cultivating the innovation ability of vocational students.

\subsubsection{Secondary Indicators of Ability to Analyze Problems}

To solve a problem, we must first conduct a thorough analysis of the problem, analyze the inherent contradictions of the problem, and analyze the key to the problem [6]. Thoroughly analyze the problem from different perspectives, find out the ideas, methods and goals to be achieved to solve the problem, and then conduct and clear the divergent thinking, so that our analysis is more extensive, universal and creative. The ability to analyze problems has been introduced in four aspects: logical thinking ability, information retrieval ability, basic knowledge level, and cross-knowledge ability. The four variables are analyzed below. The secondary indicators are shown in Table 8 .

Table 8. Secondary indicators of problem analysis ability

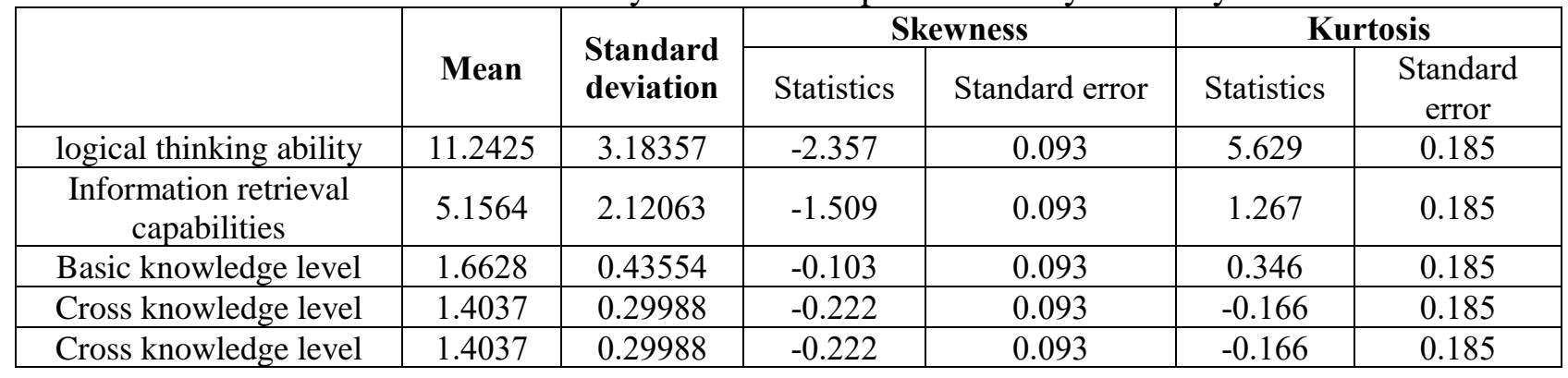

It can be seen from the above table that the average logical thinking ability is the highest, followed by the information retrieval ability, with the cross-knowledge level being the lowest, but the standard deviation in the logical thinking ability is also the largest, and the standard deviation of the crossknowledge level is the smallest. This shows that the interviewed vocational students are seriously polarized in their logical thinking ability, and most of them have strong abilities, but they are generally insufficient in cross-knowledge levels and urgently need to be strengthened. This shows that the degree of acceptance in related fields is relatively low. Higher vocational students often fail to integrate knowledge in the professional courses, but just rigidly use them in a rigid or patterned manner. Therefore, we can strengthen the teaching of practical use in related science and engineering courses or life practice, and carry out related activities to strengthen the abilities of higher vocational students in this area.

\subsubsection{Secondary Indicators of Problem-solving Ability}

"Problem solving" will be a continuous upward and limitless process that accompanies a person's life. It truly reflects a person's innovative ability and how important it is to improve the ability of innovation to solve problems. The three indicators for solving problems are project self-satisfaction, innovation activity results, and project unique level. The secondary indicators are shown in Table 9. 
Table 9. Secondary indicators of Problem-solving ability

\begin{tabular}{|c|c|c|c|c|c|c|}
\hline & \multirow{2}{*}{ Mean } & \multirow{2}{*}{$\begin{array}{c}\text { Standard } \\
\text { deviation }\end{array}$} & \multicolumn{2}{|c|}{ Skewness } & \multicolumn{2}{|c|}{ Kurtosis } \\
\cline { 5 - 7 } & & & Statistics & $\begin{array}{c}\text { Standard } \\
\text { error }\end{array}$ & Statistics & $\begin{array}{c}\text { Standard } \\
\text { error }\end{array}$ \\
\hline Subject self-satisfaction & 0.8644 & 0.63163 & 0.58 & 0.093 & 4.316 & 0.185 \\
\hline $\begin{array}{c}\text { Results of innovation } \\
\text { activities }\end{array}$ & 2.175 & 1.2958 & 0.335 & 0.093 & -0.64 & 0.185 \\
\hline Subject unique level & 1.1557 & 1.79176 & 2.728 & 0.093 & 9.415 & 0.185 \\
\hline
\end{tabular}

\section{Conclusion}

Higher vocational students in school have a relatively sufficient understanding of innovation consciousness, but restricted by various factors, innovation cognition and practice are seriously deviated. The cultivation of innovation awareness and ability of vocational students is not accomplished overnight. It is necessary to carefully analyze the main factors affecting the cultivation of innovation ability of vocational students, recognize the current deficiencies of education in the cultivation of innovation awareness of vocational students, prescribe the right medicine, and make timely adjustments and adjustments. Reform, create a set of educational models and teaching methods suitable for the cultivation of innovative consciousness of higher vocational students, realize innovative education through educational innovation, and cultivate a generation of innovative talents with good innovative consciousness in colleges and universities.

\section{Acknowledgments}

Fund Project: Social Science Project of the 13th Five-Year Plan of Jilin Provincial Department of Education "Research on Practice Platform and Operation Mode of Innovation and Entrepreneurship for Higher Vocational College Students" (JJKH20200229JY).

\section{References}

[1] Kristinae, V. Wardana, I. Giantari, I. G. A. K. \& Rahyuda, A. The role of powerful business strategy on value innovation capabilities to improve marketing performance during the COVID-19 pandemic. Uncertain Supply Chain Management, vol. 8, pp.675-684, April 2020.

[2] Li, Z. Liao, G. \& Albitar, K. Does corporate environmental responsibility engagement affect firm value? The mediating role of corporate innovation. Business Strategy and the Environment, vol. 29, pp. 10451055, March 2020.

[3] Zhao, Q. Tsai, P. H. \& Wang, J. L. (2019). Improving financial service innovation strategies for enhancing China's banking industry competitive advantage during the fintech revolution: A Hybrid MCDM model. Sustainability, vol. 11, pp.1419-1429, May 2019.

[4] Cillo, V. Petruzzelli, A. M. Ardito, L. \& Del Giudice, M. Understanding sustainable innovation: A systematic literature review. Corporate Social Responsibility and Environmental Management, vol. 26, pp. 1012-1025, May 2019.

[5] Supriadi, O. Musthan, Z. Sa'odah, R. N. Haryanti, Y. D. Marwal, M. R. Purwanto, A. \& Sumartiningsih, S. Did transformational, transactional leadership style and organizational learning influence innovation capabilities of school teachers during covid-19 pandemic? Systematic Reviews in Pharmacy, vol. 11, pp. 299-311, September 2020.

[6] Wang, S. Zhang, J. Fan, F. Lu, F. \& Yang, L. The symbiosis of scientific and technological innovation efficiency and economic efficiency in China--An analysis based on data envelopment analysis and logistic model. Technology Analysis \& Strategic Management, vol. 31, pp. 67-80, January 2019. 